\title{
Thermodynamic Modeling of an Atkinson Cycle with respect to Relative Air-Fuel Ratio, Fuel Mass Flow Rate and Residual Gases
}

\begin{abstract}
R. EBRAHIMi*
Department of Agriculture Machine Mechanics, Shahrekord University, P.O. Box 115, Shahrekord, Iran

(Received March 26, 2013; in final form April 17, 2013)

The performance of an air standard Atkinson cycle is analyzed using finite-time thermodynamics. The results show that if the compression ratio is less than a certain value, the power output increases with increasing relative air-fuel ratio, while if the compression ratio exceeds a certain value, the power output first increases and then starts to decrease with increase of relative air-fuel ratio. With a further increase in compression ratio, the increase in relative air-fuel ratio results in decrease of the power output. Throughout the compression ratio range, the power output increases with increase of fuel mass flow rate. The results also show that if the compression ratio is less than a certain value, the power output increases with increase of residual gases, on the contrast, if the compression ratio exceeds a certain value, the power output decreases with increase of residual gases. The results obtained herein can provide guidance for the design of practical Atkinson engines.
\end{abstract}

DOI: 10.12693/APhysPolA.124.29

PACS: 05.70.Ln, 82.60.Fa, 88.05.-b

\section{Introduction}

The Atkinson cycle is a type of internal combustion engine, which was designed and built by a British engineer James Atkinson in 1882. The cycle is also called the Sargent cycle by several physics-oriented thermodynamic books. The Atkinson cycle engine mainly works at part load operating conditions especially in the middle to high load range when it is used in a hybrid vehicle [1]. For example, Toyota in its Prius II uses a spark ignition engine which achieves high efficiency by using a Atkinson cycle based on variable valve timing management [2].

In the last two decades there have been many efforts in developing finite-time thermodynamics [3-7]. Several authors have examined the finite-time thermodynamic performance of the reciprocating heat engines [8-11]. Leff [12] determined the thermal efficiency of a reversible Atkinson engine cycle at maximum work output. Ge et al. $[13,14]$ studied the effect of variable specific heat of the working fluid on the performance of endoreversible and irreversible Atkinson cycles. Hou [15] compared the performances of air standard Atkinson and Otto cycles with heat transfer loss considerations. The results show that the Atkinson cycle has a greater work output and a higher thermal efficiency than the Otto cycle at the same operating condition.

The compression ratios that maximize the work of the Otto cycle are always found to be higher than those for the Atkinson cycle at the same operating conditions. Lin and Hou [16] investigated the effects of heat loss, as characterized by a percentage of fuel's energy, friction and variable specific heats of the working fluid, on the per-

*e-mail: Rahim.Ebrahimi@gmail.com formance of an air standard Atkinson cycle under the restriction of the maximum cycle temperature. The results show that the power output as well as the efficiency, for which the maximum power-output occurs, will rise with the increase of maximum cycle temperature.

The temperature dependent specific heats of the working fluid have a significant influence on the performance. Chen et al. [17] built a class of generalized irreversible universal steady flow heat engine cycle model consisting of two heating branches, two cooling branches, and two adiabatic branches with consideration of the losses of heat resistance, heat leakage, and internal irreversibility. The performance characteristics of Diesel, Otto, Brayton, Atkinson, dual and Miller cycles were derived.

Thermodynamic analysis of an ideal air standard Atkinson cycle with temperature dependent specific heat is presented by Al-Sarkhi et al. [18]. This paper outlines the effect of maximizing power density on the performance of the cycle efficiency. Chen et al. [19] analyzed the performance characteristics of endoreversible and irreversible reciprocating Diesel, Otto, Atkinson, Brayton, Braysson, Carnot, dual, and Miller cycles with constant and variable specific heats of the working fluid. Ust [20] made a comparative performance analysis and optimization of irreversible Atkinson cycle under maximum power density and maximum power conditions. It is shown that for the Atkinson cycle, a design based on the maximum power density conditions is more advantageous from the point of view of engine sizes and thermal efficiency. Liu and Chen [21] investigated the influence of variable heat capacities of the working fluid, heat leak losses, compression and expansion efficiencies and other parameters on the optimal performance of the Otto, Brayton, Miller, Diesel and Atkinson cycles. Ebrahimi [22] analyzed the effects of the variable residual gases of working fluid on the performance of an endoreversible Atkinson cycle. Ebrahimi [23] also investigated the effects of the 
mean piston speed, the equivalence ratio and the cylinder wall temperature on the performance of an irreversible Atkinson cycle. On the basis of research workers [12-23], effects of relative air-fuel ratio, fuel mass flow rate and residual gases on the performance of the air standard Atkinson cycle are derived in this paper.

\section{Thermodynamic analysis}

The pressure--volume $(P-V)$ and the temperatureentropy $(T-S)$ diagrams of an irreversible Atkinson heat engine is shown in Fig. 1 , where $T_{1}, T_{2 \mathrm{~s}}, T_{2}, T_{3}, T_{4}$, and $T_{4 \mathrm{~s}}$ are the temperatures of the working substance in state points $1,2 \mathrm{~s}, 2,3,4$, and $4 \mathrm{~s}$. Process $1 \rightarrow 2 \mathrm{~s}$ is a reversible adiabatic compression, while process $1 \rightarrow 2$ is an irreversible adiabatic process that takes into account the internal irreversibility in the real compression process. Heat addition is an isochoric process $2 \rightarrow 3$. Process $3 \rightarrow 4$ s is a reversible adiabatic expansion, while $3 \rightarrow 4$ is an irreversible adiabatic process that takes into account the internal irreversibility in the real expansion process. The heat-removing process is the reversible constant pressure $4 \rightarrow 1$.
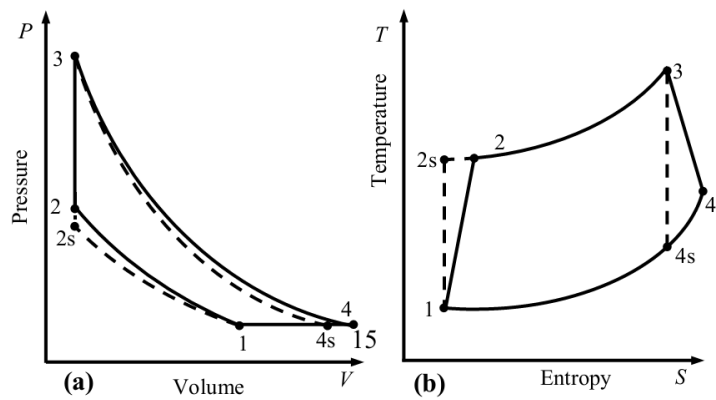

Fig. 1. (a) $P-V$ diagram, (b) $T-S$ diagram for the air standard Atkinson cycle.

The relations between the mass flow rate of the fuel $\left(\dot{m}_{\mathrm{f}}\right)$ and the mass flow rate of the air $\left(\dot{m}_{\mathrm{a}}\right)$, between $\dot{m}_{\mathrm{f}}$ and the mass flow rate of the air-fuel mixture $\left(\dot{m}_{\mathrm{t}}\right)$ are defined as [24, 25]:

$$
\dot{m}_{\mathrm{a}}=\dot{m}_{\mathrm{f}} \lambda\left(\frac{m_{\mathrm{a}}}{m_{\mathrm{f}}}\right)_{\mathrm{s}}
$$

and

$$
\dot{m}_{\mathrm{t}}=\frac{\dot{m}_{\mathrm{f}}\left[1+\lambda\left(\frac{m_{\mathrm{a}}}{m_{\mathrm{f}}}\right)_{\mathrm{s}}\right]}{1-x_{\mathrm{r}}},
$$

where $m_{\mathrm{a}} / m_{\mathrm{f}}$ is the air-fuel ratio and the subscript $\mathrm{s}$ denotes stoichiometric conditions, $\lambda$ is the relative airfuel ratio and $x_{\mathrm{r}}$ is the residual fraction from the previous cycle, and one can find it as

$$
x_{\mathrm{r}}=\frac{m_{\mathrm{r}}}{m_{\mathrm{a}}+m_{\mathrm{f}}+m_{\mathrm{r}}},
$$

where $m_{\mathrm{r}}$ is the mass of residual gases. It should be noted here that the residual gases were assumed to consist of $\mathrm{CO}_{2}, \mathrm{H}_{2} \mathrm{O}$ and $\mathrm{N}_{2}$.

The mass specific heat at constant volume for the working fluid $\left(C_{\mathrm{vt}}\right)$ is defined as:

$$
C_{\mathrm{vt}}=\frac{\left(1-x_{\mathrm{r}}\right)\left[\lambda\left(\frac{m_{\mathrm{a}}}{m_{\mathrm{f}}}\right)_{\mathrm{s}} C_{\mathrm{va}}+C_{\mathrm{vf}}\right]+x_{\mathrm{r}} C_{\mathrm{vr}}\left[1+\lambda\left(\frac{m_{\mathrm{a}}}{m_{\mathrm{f}}}\right)_{\mathrm{s}}\right]}{1+\lambda\left(\frac{m_{\mathrm{a}}}{m_{\mathrm{f}}}\right)_{\mathrm{s}}}
$$

where $C_{\mathrm{va}}, C_{\mathrm{vf}}$ and $C_{\mathrm{vr}}$ are the mass specific heat at constant volume for air, fuel and residual gases, respectively.

The mass specific heat at constant pressure for the working fluid $\left(C_{\mathrm{pt}}\right)$ is defined as:

$$
C_{\mathrm{pt}}=\frac{\left(1-x_{\mathrm{r}}\right)\left[\lambda\left(\frac{m_{\mathrm{a}}}{m_{\mathrm{f}}}\right)_{\mathrm{s}} C_{\mathrm{pa}}+C_{\mathrm{pf}}\right]+x_{\mathrm{r}} C_{\mathrm{pr}}\left[1+\lambda\left(\frac{m_{\mathrm{a}}}{m_{\mathrm{f}}}\right)_{\mathrm{s}}\right]}{1+\lambda\left(\frac{m_{\mathrm{a}}}{m_{\mathrm{f}}}\right)_{\mathrm{s}}}
$$

where $C_{\mathrm{pa}}, C_{\mathrm{pf}}$ and $C_{\mathrm{pr}}$ are the mass specific heat at constant pressure for air, fuel and residual gases, respectively.

The heat added per second in the isochoric $(2 \rightarrow 3)$ heat addition process may be written as

$$
\begin{aligned}
& \dot{Q}_{\text {in }}=\dot{m}_{\mathrm{t}} C_{\mathrm{vt}}\left(T_{3}-T_{2}\right) \\
& =\dot{m}_{\mathrm{f}}\left\{\left(1-x_{\mathrm{r}}\right)\left[\lambda\left(\frac{m_{\mathrm{a}}}{m_{\mathrm{f}}}\right)_{\mathrm{s}} C_{\mathrm{va}}+C_{\mathrm{vf}}\right]\right. \\
& \left.+x_{\mathrm{r}} C_{\mathrm{vr}}\left[1+\lambda\left(\frac{m_{\mathrm{a}}}{m_{\mathrm{f}}}\right)_{\mathrm{s}}\right]\right\} \frac{T_{3}-T_{2}}{1-x_{\mathrm{r}}}
\end{aligned}
$$

where $T$ is the absolute temperature.

The heat rejected in the isobaric heat rejection process $(4 \rightarrow 1)$ may be written as

$$
\begin{gathered}
\dot{Q}_{\text {out }}=\dot{m}_{\mathrm{t}} C_{\mathrm{pt}}\left(T_{4}-T_{1}\right)=\dot{m}_{\mathrm{f}}\left\{( 1 - x _ { \mathrm { r } } ) \left[\lambda\left(\frac{m_{\mathrm{a}}}{m_{\mathrm{f}}}\right)_{\mathrm{s}} C_{\mathrm{pa}}\right.\right. \\
\left.\left.+C_{\mathrm{pf}}\right]+x_{\mathrm{r}} C_{\mathrm{pr}}\left[1+\lambda\left(\frac{m_{\mathrm{a}}}{m_{\mathrm{f}}}\right)_{\mathrm{s}}\right]\right\} \frac{T_{4}-T_{1}}{1-x_{\mathrm{r}}} .
\end{gathered}
$$

The total energy of the fuel per second input into the engine, of a gasoline type fuel, such as octane, can be expressed in terms of equivalence ratio factor from measured data as $[25,26]$ :

$$
\begin{aligned}
& \dot{Q}_{\text {fuel }}=\eta_{\text {com }} \dot{m}_{\mathrm{f}} Q_{\mathrm{LHV}}=(-1.44738+4.18581 \lambda \\
& \left.-1.86876 \lambda^{2}\right) \dot{m}_{\mathrm{f}} Q_{\mathrm{LHV}},
\end{aligned}
$$

where $\eta_{\text {com }}$ is the combustion efficiency, $Q_{\mathrm{LHV}}$ is the lower calorific value of the fuel.

Besides the irreversibility of the adiabatic processes, the heat transfer irreversibility between the working fluid and the cylinder wall is not negligible.

For an ideal Atkinson cycle model, there are no heat transfer losses. However, for a real Atkinson cycle, heat transfer irreversibility between the working fluid and the cylinder wall is not negligible. If the heat leakage coefficient of the cylinder wall is $B$, the heat loss through the cylinder wall is given in the following linear expression $[19,25]$ :

$$
\begin{aligned}
& \dot{Q}_{\mathrm{ht}}=\dot{m}_{\mathrm{t}} B\left(T_{2}+T_{3}-2 T_{0}\right)=\dot{m}_{\mathrm{f}} B\left[1+\lambda\left(\frac{m_{\mathrm{a}}}{m_{\mathrm{f}}}\right)_{\mathrm{s}}\right] \\
& \quad \times \frac{T_{2}+T_{3}-2 T_{0}}{1-x_{\mathrm{r}}} .
\end{aligned}
$$

It is assumed that the heat loss through the cylinder wall is proportional to the average temperature of both the working fluid and the cylinder wall and that the wall temperature is constant at $T_{0}$. Equation (9) implies the fact that there is a heat leak loss in the combustion process. 
Since the total energy of the delivered fuel $\dot{Q}_{\text {fuel }}$ is assumed to be the sum of the heat added to the working fluid $\dot{Q}_{\text {in }}$ and the heat leakage $\dot{Q}_{\mathrm{ht}}$,

$$
\begin{aligned}
& \dot{Q}_{\text {in }}=\dot{Q}_{\text {fuel }}-\dot{Q}_{\mathrm{ht}}=(-1.44738+4.18581 \lambda \\
& \left.-1.86876 \lambda^{2}\right) \dot{m}_{\mathrm{f}} Q_{\mathrm{LHV}}-\dot{m}_{\mathrm{f}} B\left[1+\lambda\left(\frac{m_{\mathrm{a}}}{m_{\mathrm{f}}}\right)_{\mathrm{s}}\right] \\
& \times \frac{T_{2}+T_{3}-2 T_{0}}{1-x_{\mathrm{r}}} .
\end{aligned}
$$

For the two adiabatic processes, the compression and expansion efficiencies $[20,21]$ :

$$
\begin{aligned}
\quad \eta_{\mathrm{c}} & =\left(T_{2 \mathrm{~s}}-T_{1}\right) /\left(T_{2}-T_{1}\right) \\
\text { and } & \\
\eta_{\mathrm{e}} & =\left(T_{4}-T_{3}\right) /\left(T_{4 \mathrm{~s}}-T_{3}\right) .
\end{aligned}
$$

These two efficiencies can be used to describe the internal irreversibility of the processes.

The specific compression, $r_{\mathrm{c}}^{*}$, and compression, $r_{\mathrm{c}}$, ratios are defined as:

$$
r_{\mathrm{c}}^{*}=V_{1} / V_{2}
$$

and

$$
r_{\mathrm{c}}=V_{4} / V_{2}=T_{4} /\left(T_{1} r_{\mathrm{c}}^{*}\right) .
$$

Therefore

$$
T_{2 \mathrm{~s}}=T_{1}\left(r_{\mathrm{c}}^{*}\right)^{\frac{\left[1-x_{\mathrm{r}}\right]\left[\lambda\left(\frac{m_{\mathrm{a}}}{m_{\mathrm{f}}}\right)_{\mathrm{s}} C_{\mathrm{pa}}+C_{\mathrm{pf}}\right]+x_{\mathrm{r}} C_{\mathrm{pr}}\left[1+\lambda\left(\frac{m_{\mathrm{a}}}{m_{\mathrm{f}}}\right)_{\mathrm{s}}\right]}{\left[1-x_{\mathrm{r}}\right]\left[\lambda\left(\frac{m_{\mathrm{a}}}{m_{\mathrm{f}}}\right)_{\mathrm{s}} C_{\mathrm{va}}+C_{\mathrm{vf}}\right]+x_{\mathrm{r}} C_{\mathrm{vr}}\left[1+\lambda\left(\frac{m_{\mathrm{a}}}{m_{\mathrm{f}}}\right)_{\mathrm{s}}\right]}}-1
$$

and

$$
T_{4 \mathrm{~s}}=T_{1}\left(\frac{T_{3}}{T_{2}}\right)^{\left.\left.\frac{\left[1-x_{\mathrm{r}}\right]\left[\lambda\left(\frac{m_{\mathrm{a}}}{m_{\mathrm{f}}}\right)_{\mathrm{s}} C_{\mathrm{va}}+C_{\mathrm{vf}}\right]+x_{\mathrm{r}} C_{\mathrm{vr}}\left[1+\lambda\left(\frac{m_{\mathrm{a}}}{m_{\mathrm{f}}}\right)_{\mathrm{s}}\right]}{m_{\mathrm{f}}}\right)_{\mathrm{s}} C_{\mathrm{pa}}+C_{\mathrm{pf}}\right]+x_{\mathrm{r}} C_{\mathrm{pr}}\left[1+\lambda\left(\frac{m_{\mathrm{a}}}{m_{\mathrm{f}}}\right)_{\mathrm{s}}\right]} .
$$

Taking into account the friction loss of the piston and assuming a dissipation term represented by a friction force that is a linear function of the piston velocity gives [19]

$$
f_{\mu}=-\mu v=-\mu \frac{\mathrm{d} x}{\mathrm{~d} t},
$$

where $\mu$ is the coefficient of friction, which takes into account the global losses, $x$ is the piston's displacement and $v$ is the piston's velocity. Therefore, the lost power due to friction is

$$
P_{\mu}=\frac{\mathrm{d} W_{\mu}}{\mathrm{d} t}=-\mu\left(\frac{\mathrm{d} x}{\mathrm{~d} t}\right)^{2}=-\mu v^{2} .
$$

Running at $N$ revolutions per second, the mean velocity of the piston is [25]:

$$
\bar{v}=2 L N=2 L^{*}\left[\frac{T_{4} /\left(T_{1} r_{\mathrm{c}}^{*}\right)-1}{r_{\mathrm{c}}^{*}-1}\right] N,
$$

where $L$ is the total distance the piston travels per cycle and $L^{*}$ is the length of the isentropic process $1 \rightarrow 2$.

The power output of the Atkinson cycle engine is expressed by

$$
\begin{aligned}
& P_{\text {out }}=\frac{W}{\tau}-\left|P_{\mu}\right|=\frac{\dot{m}_{\mathrm{f}}}{1-x_{\mathrm{r}}}\left(\left\{( 1 - x _ { \mathrm { r } } ) \left[\lambda\left(\frac{m_{\mathrm{a}}}{m_{\mathrm{f}}}\right)_{\mathrm{s}} C_{\mathrm{va}}\right.\right.\right. \\
& \left.\left.+C_{\mathrm{vf}}\right]+x_{\mathrm{r}} C_{\mathrm{vr}}\left[1+\lambda\left(\frac{m_{\mathrm{a}}}{m_{\mathrm{f}}}\right)_{\mathrm{s}}\right]\right\}\left(T_{3}-T_{2}\right) \\
& -\left\{\left(1-x_{\mathrm{r}}\right)\left[\lambda\left(\frac{m_{\mathrm{a}}}{m_{\mathrm{f}}}\right)_{\mathrm{s}} C_{\mathrm{pa}}+C_{\mathrm{pf}}\right]\right.
\end{aligned}
$$

$$
\begin{aligned}
& \left.\left.+x_{\mathrm{r}} C_{\mathrm{pr}}\left[1+\lambda\left(\frac{m_{\mathrm{a}}}{m_{\mathrm{f}}}\right)_{\mathrm{s}}\right]\right\}\left(T_{4}-T_{1}\right)\right) \\
& -4 \mu\left[\frac{L^{*} N\left(T_{4} /\left(T_{1} r_{\mathrm{c}}^{*}\right)-1\right)}{r_{\mathrm{c}}^{*}-1}\right]^{2} .
\end{aligned}
$$

The efficiency of the cycle is

$$
\begin{gathered}
\eta_{\mathrm{th}}=\frac{P_{\mathrm{out}}}{Q_{\mathrm{in}}} \times 100=P_{\mathrm{out}} /\left(\frac { \dot { m } _ { \mathrm { f } } ( T _ { 3 } - T _ { 2 } ) } { 1 - x _ { \mathrm { r } } } \left\{\left(1-x_{\mathrm{r}}\right)\right.\right. \\
\left.\left.\times\left[\lambda\left(\frac{m_{\mathrm{a}}}{m_{\mathrm{f}}}\right)_{\mathrm{s}} C_{\mathrm{va}}+C_{\mathrm{vf}}\right]+x_{\mathrm{r}} C_{\mathrm{vr}}\left[1+\lambda\left(\frac{m_{\mathrm{a}}}{m_{\mathrm{f}}}\right)_{\mathrm{s}}\right]\right\}\right)
\end{gathered}
$$$$
\times 100 \text {. }
$$

When $r_{\mathrm{c}}^{*}, \eta_{\mathrm{c}}, \eta_{\mathrm{e}},\left(\frac{m_{\mathrm{a}}}{m_{\mathrm{f}}}\right)_{\mathrm{s}}, C_{\mathrm{va}}, C_{\mathrm{vf}}, C_{\mathrm{vr}}, C_{\mathrm{pa}}, C_{\mathrm{pf}}, C_{\mathrm{pr}}, B$, $N, T_{0}, \mu, L, Q_{\mathrm{LHV}}, \dot{m}_{\mathrm{f}}, x_{\mathrm{r}}, \lambda$, and $T_{1}$ are given, $T_{2 \mathrm{~s}}$ can be obtained from Eq. (15), then, substituting $T_{2 \mathrm{~s}}$ into Eq. (11) yields $T_{2}$. $T_{3}$ can be deduced by substituting Eq. (6) into Eq. (10). $T_{4 \mathrm{~s}}$ can be found from Eq. (16), and $T_{4}$ can be deduced by substituting $T_{4 \mathrm{~s}}$ into Eq. (12). Substituting $T_{1}, T_{2}, T_{3}$, and $T_{4}$ into Eqs. (20) and (21), respectively, the power output and the thermal efficiency of the Atkinson cycle engine can be obtained. Therefore, the relations between the power output, the thermal efficiency and the compression ratio can be derived.

\section{Results and discussion}

According to Refs. [17-24], the following parameters are used in the calculations: $\eta_{\mathrm{c}}=0.97, \eta_{\mathrm{e}}=$ $0.97, \quad\left(m_{\mathrm{a}} / m_{\mathrm{f}}\right)_{\mathrm{s}}=15.1, \quad C_{\mathrm{va}}=0.717 \mathrm{~kJ} / \mathrm{kgK}$, $C_{\mathrm{vf}}=1.638 \mathrm{~kJ} / \mathrm{kgK}, \quad C_{\mathrm{vr}}=0.8268 \mathrm{~kJ} / \mathrm{kgK}$ $C_{\mathrm{pa}}=1.004 \mathrm{~kJ} / \mathrm{kgK}, C_{\mathrm{pf}}=1.711 \mathrm{~kJ} / \mathrm{kgK}, C_{\mathrm{pr}}=$ $1.1335 \mathrm{~kJ} / \mathrm{kg} \mathrm{K}, T_{1}=350 \mathrm{~K}, B=1.3 \mathrm{~kJ} \mathrm{~kg}^{-1} \mathrm{~K}^{-1}, N=$ $3000 \mathrm{rpm}, T_{0}=430 \mathrm{~K}, \mu=12.9 \mathrm{~N} \mathrm{~s} \mathrm{~m}^{-1}, L=80 \mathrm{~mm}$, $Q_{\mathrm{LHV}}=44347 \mathrm{~kJ} \mathrm{~kg}^{-1}, \dot{m}_{\mathrm{f}}=0.0015 \rightarrow 0.003 \mathrm{~kg} \mathrm{~s}^{-1}$, $x_{\mathrm{r}}=5 \% \rightarrow 20 \%$ and $\lambda=0.9 \rightarrow 1.2$.

The variations in the temperatures $T_{2}, T_{3}$ and $T_{4}$ with the compression ratio are shown in Fig. 2. It is found that $T_{2}$ increases with the increase of compression ratio, while $T_{3}$ and $T_{4}$ decrease with the increase of compression ratio.

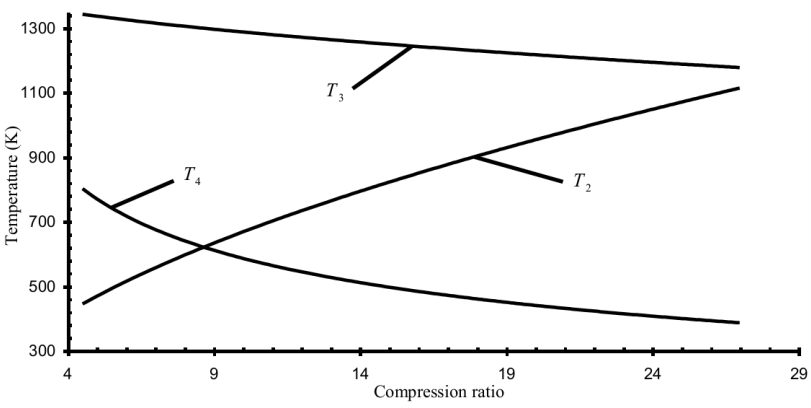

Fig. 2. The temperature versus compression ratio $\left(x_{\mathrm{r}}=20 \%, \dot{m}_{\mathrm{f}}=0.0025 \mathrm{~kg} / \mathrm{s}\right.$ and $\left.\lambda=1.0\right)$.

As it can be clearly seen from above equations, the power output and the thermal efficiency of the Atkinson cycle are dependent on the relative air-fuel ratio, 
the fuel mass flow rate and the residual gases. In order to illustrate the effects of these parameters, the relations between the power output and the compression ratio, between the power output and the thermal efficiency of the cycle are presented. It can be seen from Figs. 3-8 that an increase in compression ratio first leads to an increase in power output, and after reaching a peak, the power output decreases dramatically with further increases in compression ratio. It is found that the relative air-fuel ratio, the fuel mass flow rate and the residual gases play important roles on the performance cycle. It is clearly seen from these figures that the effects of the relative air-fuel ratio, the fuel mass flow rate and the residual gases on the power output is related to the compression ratio. They show that the maximum power output point and the maximum efficiency point are very adjacent. It should be noted that the heat added and the heat rejected by the working fluid decrease as the compression ratio increases.

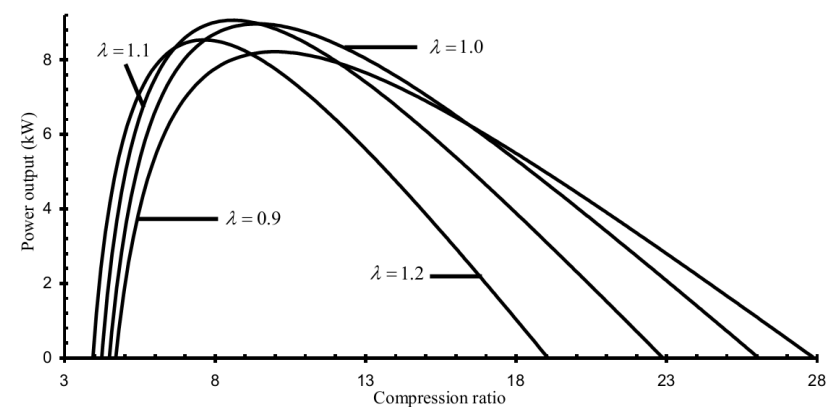

Fig. 3. Effect of relative air-fuel ratio on the variation of the power output with compression ratio $\left(x_{\mathrm{r}}=20 \%\right.$ and $\dot{m}_{\mathrm{f}}=0.0025 \mathrm{~kg} / \mathrm{s}$ ).

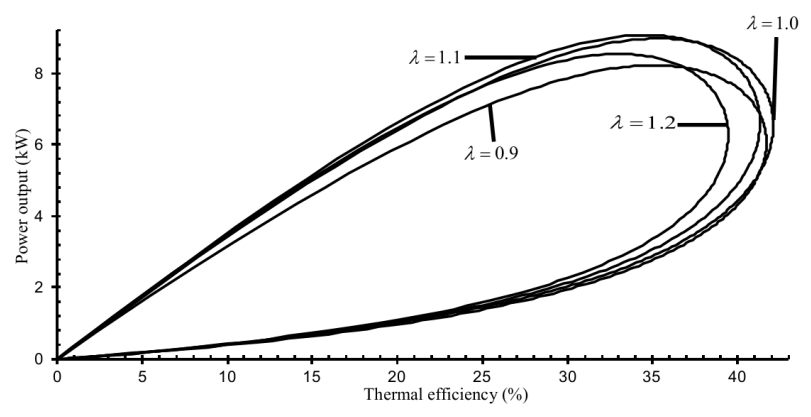

Fig. 4. Effect of relative air-fuel ratio on the variation of the power output with thermal efficiency $\left(x_{\mathrm{r}}=20 \%\right.$ and $\dot{m}_{\mathrm{f}}=0.0025 \mathrm{~kg} / \mathrm{s}$ ).

It can be concluded from Fig. 3 that if the compression ratio is less than a certain value, the power output increases with increase of relative air-fuel ratio. This can be attributed to the fact that the ratio of the heat rejected by the working fluid to the heat added by the working fluid increase with increase of relative air-fuel ratio. While if the compression ratio exceeds a certain

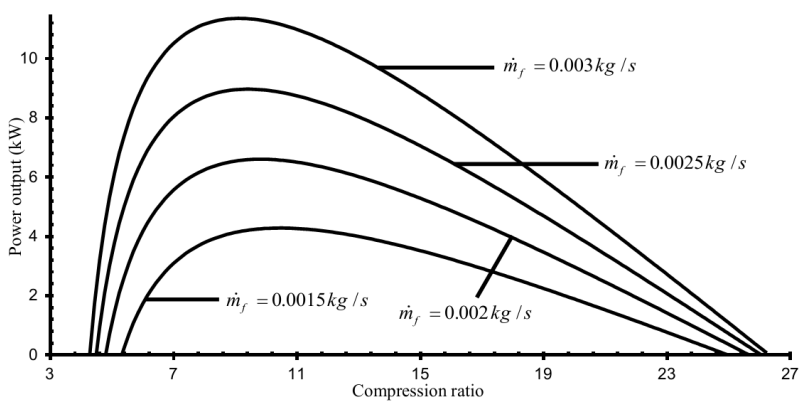

Fig. 5. Effect of fuel mass flow rate on the variation of the power output with compression ratio $\left(x_{\mathrm{r}}=20 \%\right.$ and $\lambda=1$ ).

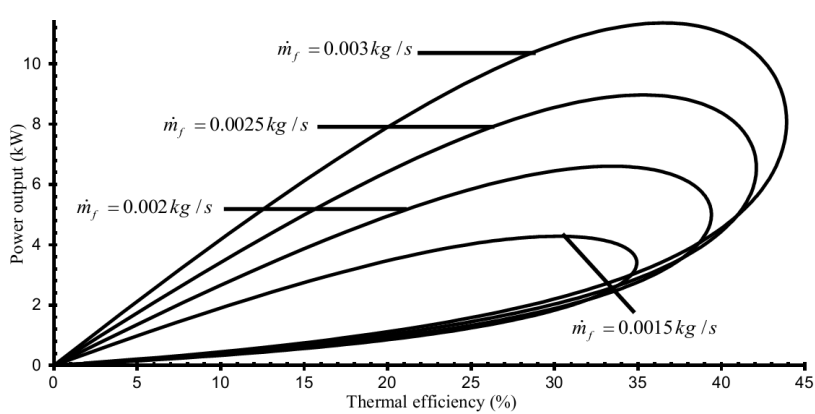

Fig. 6. Effect of fuel mass flow rate on the variation of the power output with thermal efficiency $\left(x_{\mathrm{r}}=20 \%\right.$ and $\lambda=1)$.

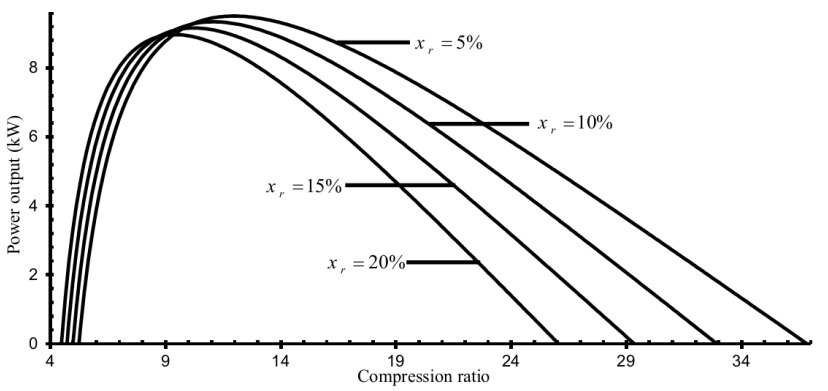

Fig. 7. Effect of residual gases on the variation of the power output with compression ratio $\left(\lambda=1.0\right.$ and $\dot{m}_{\mathrm{f}}=$ $0.0025 \mathrm{~kg} / \mathrm{s}$ ).

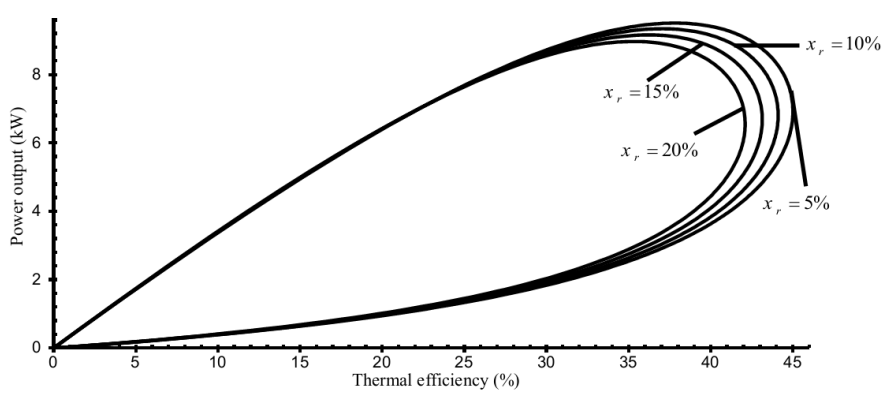

Fig. 8. Effect of residual gases on the variation of the power output with thermal efficiency $\left(\lambda=1.0\right.$ and $\dot{m}_{\mathrm{f}}=$ $0.0025 \mathrm{~kg} / \mathrm{s})$. 
value, the power output first increases and then starts to decrease with increase of relative air-fuel ratio. This can be attributed to the fact that the difference between heat added and heat rejected first increase and then starts to decrease with increase of relative air-fuel ratio. This result is consistent with the experimental results in the internal combustion engine [27].

With a further increase in compression ratio, the power output decreases with increase of relative air-fuel ratio. This is due to the increase of the heat rejected by the working fluid being more than the increase of the heat added by the working fluid. In other words, the difference between heat added and heat rejected decreases with increase of relative air-fuel ratio.

Referring to Figs. 3 and 4, it can be revealed that the maximum power output, the maximum thermal efficiency, the power output at maximum thermal efficiency, and the thermal efficiency at maximum power output first increase and then decrease as the relative air-fuel ratio increases. While the working range of the cycle and the optimal compression ratio corresponding to maximum power output point decreases as the relative airfuel ratio increases. Numerical calculation shows that for any same compression ratio, the smallest power output is for $\lambda=0.9$ when $r_{\mathrm{c}}<8.2$ and is for $\lambda=1.2$ when $r_{\mathrm{c}} \geq 8.2$, and also the largest power output is for $\lambda=1.2$ when $r_{\mathrm{c}}<8.4$, is for $\lambda=1.1$ when $8.4 \leq r_{\mathrm{c}}<9$, is for $\lambda=1$ when $9 \leq r_{\mathrm{c}}<16.5$ and is for $\lambda=0.9$ when $r_{\mathrm{c}} \geq 16.5$.

In order to illustrate the effect of the fuel mass flow rate on the performance of the Atkinson cycle, the relations between the power output and the compression ratio and between the power output and the thermal efficiency of the cycle are presented in Figs. 5 and 6 . It must be noted here that when the fuel rate increases, the amount of heat added to the working fluid increases, too. In general, the increase in the added heat is faster than the increase in the lost heat. It can be concluded from Figs. 5 and 6 that, throughout the compression ratio range, the power output increases with increase of fuel mass flow rate. This can be attributed to the fact that the difference between heat added and heat rejected, throughout the compression ratio range, increases with increase of fuel mass flow rate. This result is consistent with the experimental results in the internal combustion engine [24]. It should be noted here that the heat added and the heat rejected by the working fluid, throughout the compression ratio range, increases as the fuel mass flow rate increases.

From these figures, it can be concluded that the maximum power output, the maximum thermal efficiency, the working range of the cycle, the power output at maximum thermal efficiency, and the thermal efficiency at maximum power output improved when the fuel mass flow rate increased. However, the optimal compression ratio corresponding to maximum power output point decreases with increase of fuel mass flow rate. In this case, when the fuel mass flow rate increases by about $100 \%$, the maximum power output will increase by about $165 \%$, the maximum thermal efficiency will increase by about $25.7 \%$, the working range of the cycle will increase by about $15.8 \%$, the power output at maximum thermal efficiency will increase by about $135.3 \%$, the thermal efficiency at maximum power output will increase by about $21 \%$, and the optimal compression ratio corresponding to maximum power output point will decrease by about $17.4 \%$. It can be concluded that the effect of the fuel mass flow rate on the power output is more than the thermal efficiency.

Figures 7 and 8 indicate the effects of the parameter residual gases on the power output and the thermal efficiency of cycle for different values of the compression ratio. It can be found from Figs. 7 and 8 that if the compression ratio is less than a certain value, the increase of residual gases will increase the power output, due to the increase in the ratio of the heat added by the working fluid to the heat rejected by the working fluid. In contrast, if the compression ratio exceeds a certain value, the increase of residual gases will reduce the power output, because of the decrease in the difference between heat added and heat rejected. This result is consistent with the experimental results in the internal combustion engine [28].

From these figures, it can be concluded that the maximum power output, the maximum thermal efficiency, the compression ratio at the maximum power output, the power output at maximum thermal efficiency, the thermal efficiency at maximum power output, and the working range of the cycle decrease with increasing residual gases. For this case, when residual gases increase $15 \%$, the maximum power output, the compression ratio at the maximum power output, the maximum thermal efficiency, the working range of the cycle, the power output at maximum thermal efficiency, and the thermal efficiency at maximum power output decrease by about 6 , $18,7.1,40.9,5.4$, and $8 \%$, respectively.

According to above analysis, it can be found that the effects of the relative air-fuel ratio, the fuel mass flow rate, and the residual gases on the cycle performance are obvious, and they should be considered in practice cycle analysis in order to make the cycle model more close to the practice.

\section{Conclusions}

The effects of the relative air-fuel ratio, the fuel mass flow rate and the residual gases on the performance of an Atkinson cycle are investigated in this study. The general conclusions drawn from the results of this work are as follows:

- If the compression ratio is less than a certain value, the power output increases with increase of relative air-fuel ratio, while if the compression ratio exceeds a certain value, the power output first increases and then starts to decrease with increase of relative airfuel ratio. With a further increase in compression 
ratio, the increase in relative air-fuel ratio results in decrease of the power output.

- The increasing relative air-fuel ratio increases the maximum power output, the maximum thermal efficiency, the power output at maximum thermal efficiency and the thermal efficiency at maximum power output at first and then decreases. While the working range of the cycle and the optimal compression ratio corresponding to maximum power output point decreases as the relative air-fuel ratio increases.

- Throughout the compression ratio range, the power output increases with increase of fuel mass flow rate.

- The maximum power output, the maximum thermal efficiency, the working range of the cycle, the power output at maximum thermal efficiency and the thermal efficiency at maximum power output increase as the fuel mass flow rate increases. While the optimal compression ratio corresponding to maximum power output point decreases with increase of fuel mass flow rate.

- If the compression ratio is less than a certain value, the increase of residual gases will increase the power output. In contrast, if the compression ratio exceeds a certain value, the increase of residual gases will reduce the power output.

- The maximum power output, the maximum thermal efficiency, the compression ratio at the maximum power output, the compression ratio at the maximum thermal efficiency, and the working range of the cycle decrease with increase of residual gases.

The analysis helps us to understand the strong effects of relative air-fuel ratio, fuel mass flow rate, and residual gases on the performance of an Atkinson cycle. Therefore, the results are of great significance to provide good guidance for the performance evaluation and improvement of real Atkinson engines.

\section{Acknowledgments}

The author would like to thank the Shahrekord University for the financial support of this work.

\section{References}

[1] http://en.wikipedia.org/wiki/Atkinson_cycle.

[2] K. Nobuki, N. Kiyoshi, K. Toshihiro, Development of new 1.8-l engine for hybrid vehicles, SAE technical paper no. 2009-01-1061, 2009.

[3] P.Y. Wang, S.S. Hou, Energy Convers. Manag. 46, 2637 (2005).

[4] Y. Ust, B. Sahin, A. Safa, Acta Phys. Pol. A 120, 412 (2011).

[5] R. Ebrahimi, J. Energy Inst. 84, 38 (2011).

[6] A. Parlak, Energy Convers. Manag. 46, 351 (2005).

[7] R. Ebrahimi, Acta Phys. Pol. A 120, 384 (2011).

[8] L. Chen, F. Meng, F. Sun, Scientia Iranica 19, 1337 (2012).

[9] S.S. Hou, J.C. Lin, Acta Phys. Pol. A 120, 979 (2011).

[10] R. Ebrahimi, Comput. Math. Appl. 62, 2169 (2011).

[11] R. Ebrahimi, Acta Phys. Pol. A 117, 887 (2010).

[12] H.S. Leff, Am. J. Phys. 55, 602 (1987).

[13] Y. Ge, L. Chen, F. Sun, C. Wu, J. Energy Inst. 80 , 52 (2007).

[14] Y. Ge, L. Chen, F. Sun, C. Wu, Appl. Energy 83, 1210 (2006).

[15] S.S. Hou, Energy Convers. Manag. 48, 1683 (2007).

[16] J.C. Lin, S.S. Hou, Appl. Energy 84, 904 (2007).

[17] L. Chen, W. Zhang, F. Sun, Appl. Energy 84, 512 (2007).

[18] A. Al-Sarkhi, B. Akash, E. Abu-Nada, I. Al-Hinti, Jordan J. Mech. Industr. Eng. 2, 71 (2008).

[19] L.G. Chen, Y.L. Ge, F.R. Sun, Proc. Inst. Mech. Eng. Part D: J. Automob. Eng. 222, 1489 (2008).

[20] Y. Ust, Int. J. Thermophys 30, 1001 (2009).

[21] J. Liu, J. Chen, Int. J. Ambient Energy 31, 59 (2010).

[22] R. Ebrahimi, J. Am. Sci. 6, (2) 12 (2010).

[23] R. Ebrahimi, Math. Comput. Model. 53, 1289 (2011).

[24] R. Ebrahimi, Ph.D. Thesis, Université de Valenciennes et du Hainaut-Cambrésis, France 2006 (in French).

[25] J.B. Heywood, Internal Combustion Engine Fundamentals, Mc-Graw Hill, New York 1988.

[26] G.H. Abd Alla, Energy Convers. Manag. 43, 1043 (2002).

[27] M. Mercier, Ph.D. Thesis, Université de Valenciennes et du Hainaut Cambrésis, France 2006 (in French).

[28] A. Hocine, PhD thesis, Université de Valenciennes et du Hainaut-Cambrésis, France 2003 (in French). 